\title{
Endogenous Interleukin 6 Production in Multiple Myeloma Patients Treated with Chimeric Monoclonal Anti-IL6 Antibodies Indicates the Existence of a Positive Feed-back Loop
}

\author{
H.C.T. van Zaanen, ${ }^{*}$ R.P. Koopmans, ${ }^{\ddagger}$ L.A. Aarden,,$\|$ H.J.A.M. Rensink, ${ }^{\|}$J.M.L. Stouthard, ${ }^{\S}$ S.O. Warnaar, ${ }^{\natural}$ H.M. Lokhorst, ${ }^{\star \star}$ \\ and M.H.J. van Oers* \\ Departments of *Hematology and ${ }^{\ddagger}$ Clinical Pharmacology, ${ }^{\S}$ Metabolic Unit, Academic Medical Center, Amsterdam; ${ }^{*}$ Central Laboratory

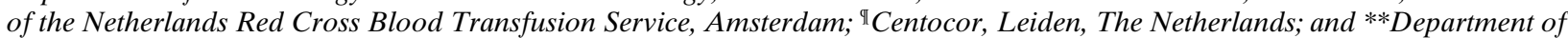 \\ Hematology, Academic Hospital Utrecht, The Netherlands
}

\section{Abstract}

In vitro as well as in vivo observations have shown that IL6 plays a key role in the pathogenesis of multiple myeloma. Therefore we started a phase I/II dose escalating study with chimeric monoclonal anti-IL6 antibodies (cMab) in multiple myeloma (MM) patients resistant to second-line chemotherapy. Here we describe the pharmacological data as well as a new method for calculating the endogenous IL6 production. The cMab (CLB IL6/8; $K_{\mathrm{d}}: 6.25 \times 10^{-12} \mathrm{M}$ ) was given in two cycles of 14 daily infusions, starting on day 1 and day 28 . Daily dose: $5 \mathrm{mg}$ in patients 1-3, $10 \mathrm{mg}$ in patients 4-6, and $20 \mathrm{mg}$ in patients 7-9 (total dose 140, 280, and $560 \mathrm{mg}$ of anti-IL6, respectively). Using the pharmacokinetic data of free IL6 and the binding characteristics of the cMab, the endogenous IL6 production could be calculated from day to day using a one-compartment open model. The median half-life time of this antibody was $\mathbf{1 7 . 6} \mathrm{d}$. No human antichimeric antibodies were induced. Pre-treatment median endogenous IL6 production in the MM patients was $60 \mu \mathrm{g} / \mathrm{d}$ (range 13.8-230; normal controls $<7 \mu \mathrm{g} / \mathrm{d}$ ).

During treatment with anti-IL6 cMabs, the endogenous IL6 production immediately decreased in all patients to below $3 \mu \mathrm{g} / \mathrm{d}$ and never reached the pre-treatment value during the treatment period, except in two patients who developed an active infection, resulting in an IL6 production of 128 and 1,208 $\mu \mathrm{g} / \mathrm{d}$, respectively. We concluded that in MM patients endogenous IL6 production is 2-30 times higher than in healthy individuals. The anti-IL6 cMab strongly suppress this endogenous IL6 production, probably by blocking a positive feed-back loop, but this cMab does not prevent infection-induced IL6 production. The chimeric anti-IL6 Mabs have a long half-life time, a low immunogenicity, and are able to block IL6-dependent processes in vivo. (J. Clin. Invest. 1996. 98:1441-1448.) Key words: multiple myeloma $\bullet$ interleukin-6 production - chimeric monoclonal antibody

Address correspondence to H.C.T. van Zaanen, Academic Medical Center, University of Amsterdam, Department of Hematology, P.O. Box 22700, 1100 DE Amsterdam, The Netherlands. Phone: 5662170; FAX: 6919743.

Received for publication 9 February 1996 and accepted in revised form 3 July 1996.

J. Clin. Invest.

(C) The American Society for Clinical Investigation, Inc.

0021-9738/96/09/1441/08 \$2.00

Volume 98, Number 6, September 1996, 1441-1448

\section{Introduction}

In the past few years research has shown that the growth of myeloma cells is regulated by cytokines. Both in vitro and in vivo observations have shown that interleukin-6 (IL6) 1 plays a key role in the pathogenesis of multiple myeloma (1-6). Especially in patients with active and/or terminal disease, serum IL6 levels have been found to be elevated $(7,8)$. Klein et al. treated a patient with plasma cell leukemia resistant to chemotherapy with daily intravenous injections of murine anti-IL6 monoclonal antibodies (Mab) for two months (9). The patient's clinical status improved and this was accompanied by a block of the myeloma cell proliferation in the bone marrow and a reduction in the serum levels of calcium, the M-protein and C-reactive protein. No major side effects were observed, but antibodies to mouse immunoglobulin could be detected 15 days after the start of the treatment. The same group recently described another eight multiple myeloma (MM) patients treated with several murine anti-IL6 Mabs in varying doses. In 2 patients a strong and in 3 other patients a weak immunization against the Mab was observed (10). Repeated administration of murine Mabs often results in the development of human anti-mouse antibodies (HAMA), frequently directed against the Fc part of the mouse immunoglobulin (11). HAMA may induce anaphylactic reactions in patients receiving murine Mabs. Moreover they lead to rapid clearance of the Mab. Based on this evidence we started a phase I/II study with chimeric anti-IL6 antibodies in MM patients who were resistant to second-line chemotherapy. The aim of the study was to evaluate the safety and efficacy of the chimeric anti-IL6 antibody in this group of patients. Here we describe the pharmacological data obtained in the first nine patients treated with this chimeric monoclonal antibody. Moreover we present a novel method to calculate the endogenous IL6 production in these patients.

\section{Methods}

Patients. All patients had MM according to the criteria of Durie and Salmon (12) and were relapsing after or resistant after at least two lines of chemotherapy (VAD [vincristine adriamycine dexamethason] or VAD-like regimens, high doses of melphalan with or without autologous bone marrow or peripheral stem cell support). Exclusion criteria were: age $<18$ or $>75$ yr, life expectancy $<3$ mo, Karnofsky score $<60$, diabetes mellitus, hypercalcemia requiring treatment, re-

1. Abbreviations used in this paper: $\mathrm{BMSC}$, bone marrow stromal cell; CLB, central laboratory of blood transfusion; CRP, c-reactive protein; HAMA, human anti-mouse antibodies; IL6, interleukin-6; MM, multiple myeloma; VAD, vincristine adriamycine dexamethason. 
cent allogeneic bone marrow transplantation, kidney and/or liver function abnormalities, coexisting malignancies, and active infection. The mean age of these 9 patients was 62.3 years (range 53-74) with a mean body mass index of $25.8(\mathrm{SEM} \pm 1.93) \mathrm{kg} / \mathrm{m}^{2}$ (Table I).

Chimeric monoclonal anti-IL6 antibody. To circumvent possible induction of HAMAs a murine-human chimeric anti-IL6 monoclonal antibody (chimeric CLB IL6/8) was developed. It is constructed of the antigen-binding variable region of the murine anti-IL6 antibody (CLB IL6/8) (13) and the constant region of a human IgG1 kappa immunoglobulin. The neutralizing Mab CLB IL6/8 blocks binding of IL6 to the IL6 receptor (CD 126) (14) and has a high affinity for recombinant as well as native IL6 $\left(K_{\mathrm{d}}=6.25 \times 10^{-12} \mathrm{M}\right)(13)$. The murine-human chimeric anti-IL6 monoclonal antibody (chimeric CLB IL6/8) was developed at Centocor, Inc., (Malvern, PA), and manufactured by Centocor Europe B.V. (Leiden, The Netherlands). The final vial contained a sterile solution of $5 \mathrm{mg}$ of chimeric CLB IL6/8 monoclonal antibody in $5 \mathrm{ml}$ of $0.15 \mathrm{M}$ sodium chloride, $0.01 \mathrm{M}$ sodium phosphate, $\mathrm{pH} 7.2$, and was tested to be pyrogen free, to pass general safety tests, and to be free of pathogenic viruses, in accordance with accepted GMP regulations and guidelines for monoclonal antibody products. The IL6 binding characteristics of CLB IL6/8 were originally characterized by the concentration of the antibody giving half-maximal inhibition of growth (I50) of the IL6-dependent hybridoma cell line (B9) (see ref. 13). For the present paper $K_{\mathrm{d}}$ was calculated from I50 in the following way. The I50 was determined by titrating CLB IL6/8 in the presence of $2 \mathrm{pg} / \mathrm{ml}$ of IL6. Each molecule of CLB IL6/8 is able to bind one IL6 molecule. In the B9-assay half-maximum growth occurs when $1 \mathrm{pg} / \mathrm{ml}$ of free IL6 is present (15). Under these conditions the I50 of the Mab CLB IL6/8 was found to be $6.25 \times 10^{-12} \mathrm{M}$. molecular weight of IL6 is $25,000 \mathrm{D}$, so the $K_{\mathrm{d}}$ can now be calculated from the following equations: [Mab] $]_{\text {total }}$ $=[\mathrm{Mab}]_{\text {free }}+[$ IL6-Mab complex $] ;[\text { IL6 }]_{\text {total }}=[\text { IL6 }]_{\text {free }}+[$ IL6-Mab complex $] ; K_{\mathrm{d}}=\left([\mathrm{IL} 6]_{\text {free }} *[\mathrm{Mab}]_{\text {free }}\right) /[$ IL6-Mab complex $]$. The latter three equations lead to $K_{\mathrm{d}}=\left([\mathrm{IL} 6]_{\text {free }} *\left([\mathrm{Mab}]_{\text {total }}-[\text { IL6 }]_{\text {total }}-\right.\right.$ $\left.[\text { IL6 }]_{\text {free }}\right) /\left([\text { IL6 }]_{\text {total }}-[\text { IL6 }]_{\text {free }}\right)$. As all of these quantities are known (see above), $K_{\mathrm{d}}$ can now be calculated to be $6.25 \times 10^{-12} \mathrm{M}$.

Treatment schedule. After obtaining written informed consent according to the guidelines of the participating institutes each patient received two cycles of treatment with chimeric monoclonal anti-IL6 antibodies. Both cycles (starting at day 1 and 28, respectively) consisted of 14 daily 2-h i.v. infusions of the cMab. Before each cycle a test dose $(10 \mu \mathrm{g})$ was given by slow i.v. push over $5 \mathrm{~min}$. As none of the nine patients developed an immediate hypersensitivity reaction, in all cases treatment was started $15 \mathrm{~min}$ later. The first three patients received a daily dose of $5 \mathrm{mg}$ of the chimeric anti-IL6 antibody (total dose 140 $\mathrm{mg}$ ), the next three patients received $10 \mathrm{mg} / \mathrm{d}$ (total dose $280 \mathrm{mg}$ ), and the last three patients received $20 \mathrm{mg} / \mathrm{d}$ (total dose $560 \mathrm{mg}$ ). Before infusion the antibody was withdrawn from the vial and diluted to a fi-

Table I. Clinical Characteristics

\begin{tabular}{|c|c|c|c|c|c|c|}
\hline & $\mathrm{M} / \mathrm{F}$ & $\begin{array}{c}\text { Age } \\
\text { years }\end{array}$ & $\mathrm{M}$ protein & Stage & Creatinine & BMI \\
\hline & & & & & $\mu \mathrm{mol} / \mathrm{l}$ & $\mathrm{kg} / \mathrm{m}^{2}$ \\
\hline 1 & M & 53 & $\operatorname{IgG\kappa }$ & IIIa & 67 & 21.6 \\
\hline 2 & $\mathrm{~F}$ & 70 & $\lambda$ & IIIa & 59 & 20.9 \\
\hline 3 & $\mathrm{~F}$ & 58 & IgGK & IIIa & 64 & 26 \\
\hline 4 & $\mathrm{~F}$ & 71 & IgGк & IIIa & 108 & 24.3 \\
\hline 5 & $\mathrm{~F}$ & 74 & $\operatorname{IgA\kappa }$ & IIIa & 123 & 25.6 \\
\hline 6 & $\mathrm{~F}$ & 63 & $\operatorname{IgG\kappa }$ & IIIa & 40 & 27.3 \\
\hline 7 & $\mathrm{~F}$ & 60 & $\operatorname{Ig} A \lambda$ & IIIa & 92 & 27.1 \\
\hline 8 & $\mathrm{~F}$ & 58 & $\operatorname{IgG\kappa }$ & IIa & 72 & 20 \\
\hline 9 & $\mathrm{~F}$ & 54 & $\operatorname{IgG\kappa }$ & IIIa & 49 & 39.5 \\
\hline Mean(SEM) & & $62.3(2.55)$ & & & $74.8(9.1)$ & $25.8(1.9)$ \\
\hline
\end{tabular}

nal volume of $250 \mathrm{ml}$ with normal saline and filtered with a low protein-binding $0.2 \mu \mathrm{m}$ filter to remove possible precipitations.

Levels of IL6 and anti-IL6 antibodies. During treatment with the chimeric CLB IL6/8 almost all IL6 in plasma was circulating in complex with the antibody (see calculations below). IL6 levels were determined with the B9 bioassay as described before (15). 5,000 B9 cells were cultured in Iscove's Modified Dulbecco's medium supplemented with $5.10^{-5} \mathrm{M}$ 2-mercaptoethanol, $5 \%$ fetal calf serum, penicillin $(100 \mathrm{IU} / \mathrm{ml})$, and streptomycin $(100 \mu \mathrm{g} / \mathrm{ml})$. The assay was carried out in flat-bottomed microtiter plates (Nunc, Roskilde, Denmark) in $200-\mu \mathrm{l}$ vol. Cells were labeled at 68 to $72 \mathrm{~h}$ with $7.4 \mathrm{kBq}$ of $\left[{ }^{3} \mathrm{H}\right]$ thymidine and the radioactivity incorporated in the nuclei was counted. Samples to be tested were always titrated in four- or fivefold dilutions and related to a standard preparation. $1 \mathrm{U}$ of B9-stimulating activity was defined as the amount inducing half-maximal proliferation and corresponded to $1 \mathrm{pg}$ of IL6. To determine the total IL6 level (i.e., free IL6 plus IL6 complexed to cMab), an excess (10 $\mu \mathrm{g} / \mathrm{ml})$ of CLB IL6/14 was added to each well to displace IL6 from its binding to the in vivo administered neutralizing chimeric CLB IL6/8. CLB IL6/14 and CLB IL6/8 Mab recognize partly overlapping sites of IL6. However, CLB IL6/14 is not capable of inhibiting IL6 activity in the B9 bioassay (16).

During treatment with the chimeric Mab actual free IL6 levels cannot be measured, because the dilution of the samples necessary for testing in the B9 bioassay or ELISA immediately influences the equilibrium between IL6-cMab complex, free IL6, and free cMab. Therefore free IL6 levels were calculated using the Henderson-Hasselbalch equation, with the $K_{\mathrm{d}}$, the daily serum cMab levels and the total IL6 levels as known parameters.

Levels of the chimeric CLB IL6/8 monoclonal antibody were determined using a Radio Immuno Assay. Briefly, the serum sample to

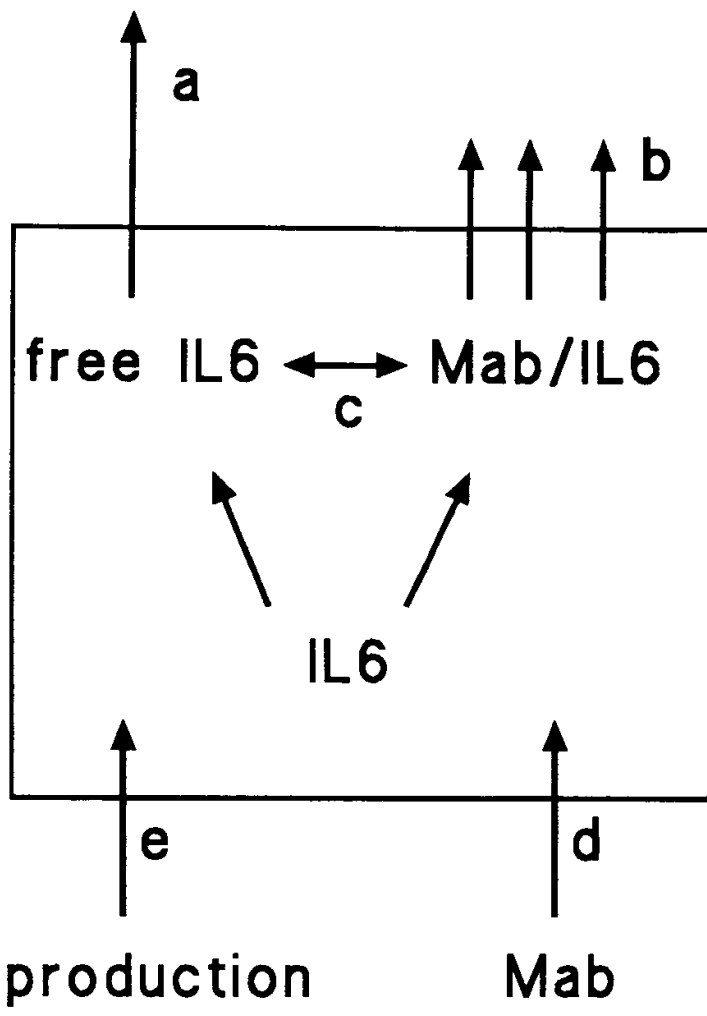

IL6 production Mab

Figure 1. Model for the calculation of the IL6 production. (a) (Rapid) clearance of free IL6. (b) Clearance of IL6 in complex with the Mab. (c) Dissociation constant. (d) Amount of Mab administered. (e) Daily IL6 production. $a-d$ are known parameters; $e$ can be calculated. 
be tested was added to $0.5 \mathrm{ml}$ of a protein A-Sepharose (Pharmacia, Uppsula, Sweden) suspension $(2 \mathrm{mg} / \mathrm{ml}$ ) in GWR (a working-solution containing $0.01 \mathrm{M}$ EDTA, $4.6 \mathrm{mM} \mathrm{NaN}_{3}, 0.3 \%$ BSA, PBS, and $0.2 \%$ Tween, $\mathrm{pH}$ 7.5) and a 1:1 dilution of the patient's pre-treatment serum. This step allows binding of all IgG immunoglobulins in the sample including the monoclonal anti-IL6 antibody. Next $50 \mu$ l of ${ }^{125}$ I-IL6 was added and after an overnight incubation the sample was washed five times with phosphate buffer saline and Tween $0.02 \%$. The amount of binding of ${ }^{125}$ I-IL6 could be counted in relation to a calibration line. The threshold of this assay is $0.5 \mathrm{ng} / \mathrm{ml}$ of antibody.

Human anti-chimeric antibody (HACA) levels were determined using an ELISA. Briefly, the cMab (CLB IL6/8) was coated overnight at room temperature $(2 \mu \mathrm{g} / \mathrm{ml}$ in $100-\mu \mathrm{l}$ well $)$ on flat-bottomed microtiter plates. Patients sera were added in different dilutions (1/50 up to 1/800) in HPE buffer (CLB Biotechnology Department, Amsterdam, The Netherlands) and incubated for $2 \mathrm{~h}$ at room temperature. After washing (PBS/Tween) plates were incubated with HRP-conjugated monoclonal mouse anti-human lambda light chain in $100 \mu \mathrm{HPE}$ buffer for $1 \mathrm{~h}$ at room temperature. Subsequently after washing the bound peroxidase was detected at $450 \mathrm{~nm}$ in a multiscan (Multiskan; Titertek, Elfab Oy, Finland).

Levels of IL6 as well as of the chimeric monoclonal antibody were determined daily from day 0 until day 14 and day 28 until day 41 (samples were drawn before starting the infusion of anti-IL6), and on day $17,21,44,48,56$, and day 100.

Mathematical procedure for calculating the overall daily production of IL6. To calculate the daily IL6 production the following data are required: pharmacokinetics of IL6 bound to cMab; pharmacokinetics of free IL6; binding characteristics of IL6 bound to the cMab.

Pharmacokinetics of the cMab CLB IL6/8. Non-lineary regression was performed using PC NONLIN version 3.0 (17). A standard onecompartment open model with bolus input was fitted to the concentration-time data of the $\mathrm{cMab}$

$C_{(t)}=\sum_{k=1}^{n} \frac{D_{k}}{V_{m a}} \cdot \exp \left(-k_{m a} \cdot\left[t-t_{D_{k}}\right]\right)$

In this equation $C(t)$ is the plasma concentration at time $t$ (days), $D_{\mathrm{k}}$ is the $k^{\text {th }}$ dose (mg), $V_{\mathrm{ma}}$ is the apparent volume of distribution (liter). $n$ is the total number of doses, $k_{\mathrm{ma}}$ is the elimination rate constant $\left(\mathrm{day}^{-1}\right), t_{\mathrm{dk}}$ is the time of administration of the $k^{\text {th }}$ dose, $k$ is a counter. A half-life time was calculated as $\ln 2 / K_{\text {ma }}$ (days).

Pharmacokinetics of free IL6. These data were derived from a study performed by one of the authors (18), in which $150 \mu \mathrm{g}$ rIL6 was infused over $240 \mathrm{~min}$, in patients with advanced renal cell carcinoma.

Table II. Pharmacokinetics of Chimeric Anti-IL6 Mab in MM Patients

\begin{tabular}{cccc}
\hline Patient & Peak serum Mab level & $t_{1 / 2}$ of Mab & Vd \\
\hline & $\mu g / m l$ & $d$ & liters \\
1 & 6.7 & 14.4 & 6.9 \\
2 & 17.2 & 39.7 & 6.0 \\
3 & 10.2 & 17.6 & 6.8 \\
4 & 44.4 & 14.0 & 3.5 \\
5 & 20.3 & 19.1 & 5.0 \\
6 & 17.9 & 12.0 & 6.7 \\
7 & 111 & 27 & 3.3 \\
8 & 30.9 & 18 & 8.6 \\
9 & 23.3 & 7.8 & 5.9 \\
Median & & 17.6 & 6.0 \\
(range) & & $(7.8-39.7)$ & $(3.3-8.6)$ \\
\end{tabular}

$M a b$, chimeric anti-IL6 monoclonal antibody. $V d$, distribution volume.
These patients had normal liver and kidney function. As to their mean age (64 y; SEM \pm 2$)$ and mean body mass index $\left(25.0 \mathrm{~kg} / \mathrm{m}^{2} \pm 1.2\right.$ $\mathrm{kg} / \mathrm{m}^{2}$ ), they were comparable to our patient group.

In this study blood samples for IL6 measurement have been taken hourly and assayed using the CLB-ELISA kit (detection limit $4 \mathrm{pg} / \mathrm{ml}$ IL6). This IL6-ELISA has a good correlation with the more sensitive B9-bioassay (19). A standard one compartment open model, with zero order input, was fitted to these data.

$C_{(t)}=\frac{\operatorname{Infu}}{V_{i l} \cdot k_{i l}} \cdot\left(1-\exp \left[-k_{i l} \cdot t\right]\right)$

where Infu is infusion rate $(\mu \mathrm{g} / \mathrm{min}), V_{\text {il }}$ (distribution volume of IL6) has dimension liters, $k_{\mathrm{il}}$ (elimination rate constant of IL6) $\mathrm{min}^{-1}, t$ min, and $C(t) \mu \mathrm{g} / \mathrm{l}$. After cessation of the infusion the equation changes to

$C(t)=C_{t_{\text {end }}} \cdot \exp \left(-k_{i l} \cdot t\right)$

where $C(t)_{\mathrm{end}}$ is the IL6 concentration at the time of stopping the infusion, and $t$ is now time after stopping the infusion. The median halflife time of IL6 was 19.5 min (range 10-37) and the median Vd of IL6 was 52.3 liters (range 23.6-66.2).

Calculation of IL6 production. To calculate daily IL6 production, the following assumptions had to be made: There is an immediate equilibrium between IL6 bound to cMab and free IL6. Moreover the in vivo $K_{\mathrm{d}}$ (dissociation constant) for this equilibrium is equal to that found in vitro (i.e., $6.25 \times 10^{-12}$ ). IL6 elimination occurs by two different routes only: by elimination of IL6 bound to the cMab and by elimination of free IL6. In our patients the parameters of free IL6 elimination (i.e., $V_{\text {il }}$ and $k_{\text {il }}$ ) are similar to those obtained in our previous study in patients with renal carcinoma (18). The elimination of the complex (cMab bound to IL6) is similar to that of free Mab (i.e. $V_{\text {ma }}$ and $k_{\text {ma }}$ ) (20). Fig. 1 schematically shows our model for calculation of the IL6 production.

For each time interval average IL6 production $\left(\operatorname{Prod}_{\text {IL6 }}(\mu \mathrm{g} / \mathrm{d})\right)$ was calculated using the following differential equation

$$
\begin{aligned}
\frac{d[I L 6]_{t o t}}{d t} & = \\
& \frac{1}{F F \cdot V_{\mathrm{il}}+(1-F F) \cdot V_{m a}} \cdot \\
& \left(I[t]-\left[F F \cdot V_{i l} \cdot k_{i l}+\{1-F F\} \cdot V_{m a} \cdot k_{m a}\right] \cdot[I 16]_{t o t}\right)
\end{aligned}
$$

This equation is an adaption of the equation used to describe the time course of a drug in a one-compartment situation, with input through continous infusion (i.e., zero order input). In this equation IL $6_{\text {total }}$ is the total serum IL6 concentration $(\mu \mathrm{g} / \mathrm{l})$, FF is the free fraction of IL6 (dimensionless) and, I(t) is the time-dependent production of IL6 $(\mu \mathrm{g} / \mathrm{d}) . V_{\mathrm{il}}, V_{\mathrm{ma}}, k_{\mathrm{ma}}$ are as defined above. $k_{\mathrm{il}}$ is also as defined above, but now expressed as units per day. Because FF was $<0.01$ at all time-points after the start of cMab dosage, the following simplifications were used: (1-FF) was equated to unity in actual computation, and $1 /\left(\mathrm{FF} . V_{\mathrm{il}}+(1-\mathrm{FF}) \cdot V_{\mathrm{ma}}\right)$ was equated to $1 / V_{\mathrm{ma}}$. The equation used for actual calculation was therefore

$$
\frac{d[I L 6]_{t o t}}{d t}=\frac{1}{V_{m a}} \cdot\left(I[t]-\left[F F \cdot V_{i l} \cdot k_{i l}+V_{m a} \cdot k_{m a}\right] \cdot[I L 6]_{t o t}\right)
$$

\section{Results}

The clinical characteristics of the nine MM patients are summarized in Table I. The preliminary clinical data have been presented earlier (21). All patients had end-stage myeloma disease and were progressive before anti-IL6 treatment. All but one patient had stable disease during anti-IL6 treatment $(\beta-2 \mathrm{M}$, paraprotein level). Despite disease stabilization in 
A

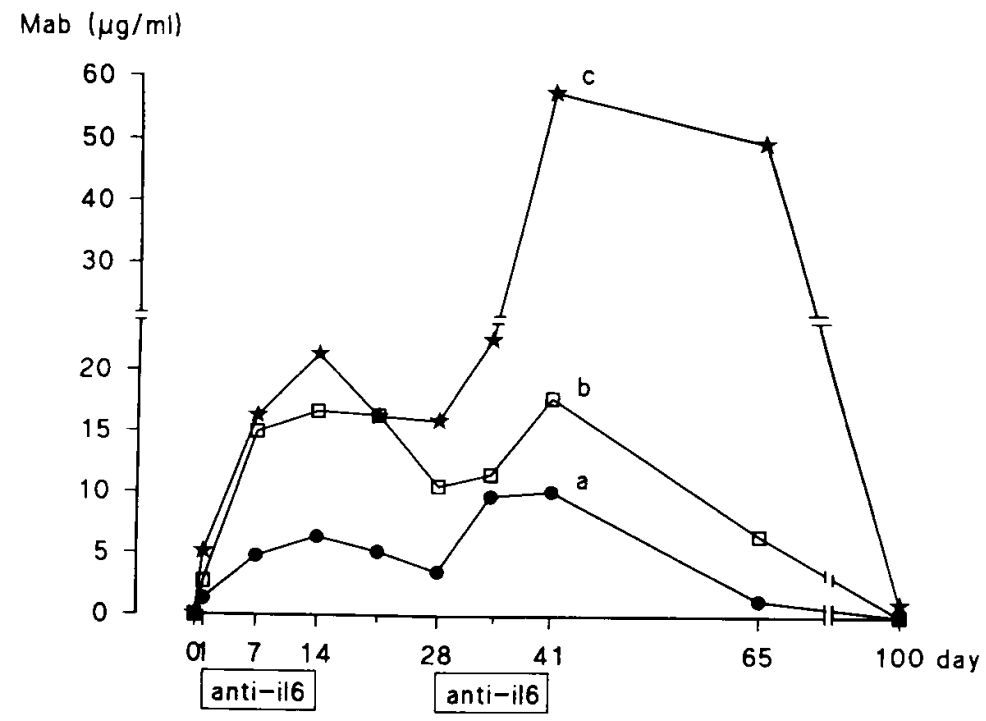

B

total IL6 $(\mathrm{pg} / \mathrm{m} \mid)$

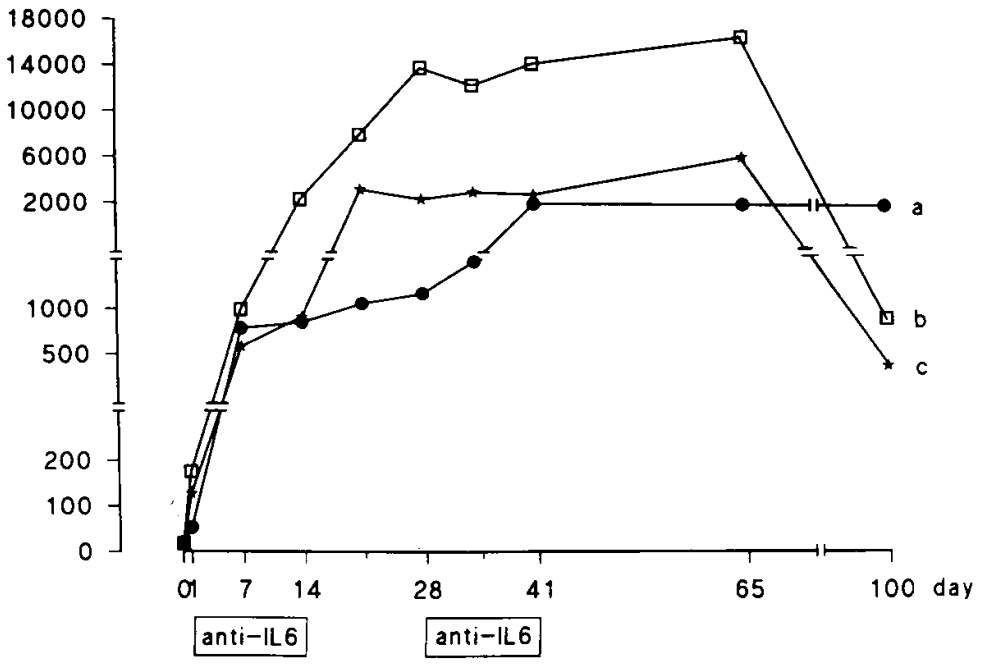

Figure 2. (A) Mean serum levels of chimeric anti-IL6Mab. (B) Mean serum levels of total IL6. (a) Patients 1-3 treated with $5 \mathrm{mg} \mathrm{Mab} / \mathrm{d}$. (b) Patients 4-6 treated with $10 \mathrm{mg} \mathrm{Mab/d.} \mathrm{(c)}$ Patients 7-9 treated with $20 \mathrm{mg} \mathrm{Mab/d}$. Not every day is plotted. On day 65 in each group two patients are present only (see Results). On day 100: $n=1$ in each group. eight of the nine patients in the present phase I/II study, no clinical responses (as defined by a decrease of the $\mathrm{M}$ protein of $>50 \%$ ) have been observed. Importantly, in these nine patients no toxicity or allergic reactions have occurred, except for a transient thrombocytopenia in patients 2 and 5 . Patient 1 received only $2 \mathrm{~d}$ of the second cycle; he went off study because he required radiotherapy for myeloma-induced neurological symptoms. Patient 5 received the first $14 \mathrm{~d}$ of treatment only because she had an active infection of the urinary tract at the time she was admitted for the second cycle. Patient 9 received anti-IL6 treatment until day 34 and went off study because of a pneumonia with septicemia.

Serum levels of cMab and IL6. Table II shows the observed peak serum levels and the calculated $t_{1 / 2}$ and $\mathrm{Vd}$ of the chimeric anti-IL6 Mab. The Vd of the cMab ranged between 3.3 and 8.6 liters. As expected the $t_{1 / 2}$ of this cMab was long with a median of
17.6 d (range 7.8-39.7 d). We did not find a correlation between the $t_{1 / 2}$ and paraprotein levels in these patients $(r=-0.15)$. Fig. $2 A$ gives the mean cMab plasma levels in $\mu \mathrm{g} / \mathrm{ml}$ for the three dosage groups. In none of the nine patients were we able to detect the induction of human anti-chimeric antibodies (HACA) within the study period of $100 \mathrm{~d}$. In agreement with this finding, there were no changes in half-life time of this cMab in the course of both treatment cycles. Total serum IL6 levels increased during therapy with the anti-IL6 cMab. The mean total IL6 levels per dosage group are shown in Fig. 2 B. Fig. 3 shows the calculated free serum IL6 levels; free IL6 levels rapidly fell to and remained below $0.5 \mathrm{pg} / \mathrm{ml}$ until day 60 , except in patient 5 and 9 . On day 100 only three patients were evaluable: in patients 6 and 8 the free IL6 levels were 2.9 and $1 \mathrm{pg} / \mathrm{ml}$, respectively (with normal CRP levels). In patient 1 free IL6 levels rose again, paralleled with disease activity. 
Table III. Pre-treatment IL6, CRP, and Endogenous IL6 Production

\begin{tabular}{cccc}
\hline Patient & Serum IL6 & Serum CRP & IL6 production \\
\hline & $p g / m l$ & $m g / l i t e r$ & $\mu g / d$ \\
1 & 50 & 8 & 230 \\
2 & 3 & $<3$ & 13.8 \\
3 & 7 & 3 & 32.2 \\
4 & 22 & 12 & 101 \\
5 & 17 & 6 & 78.2 \\
6 & 13 & 4 & 59.8 \\
7 & 10 & 6 & 20.8 \\
8 & 41 & $<3$ & 188 \\
9 & 7 & 4 & 29.4 \\
Median & 13 & 4 & 59.8 \\
(range) & $(3-50)$ & $(<3-12)$ & $(13.8-230)$
\end{tabular}

Correlation between: IL6/CRP: $r=0.34$; CRP/IL6 production: $r=0.32$; IL6/IL6 production: $r=0.99$.

Endogenous IL6 production. Table III shows the calculated endogenous IL6 production in vivo as well as CRP and IL6 plasma levels of every patient at day 0 . The pretreatment endogenous IL6 production ranged between 13.8 and $230 \mu \mathrm{g} / \mathrm{d}$ (median $60 \mu \mathrm{g} / \mathrm{d})$. We found a good correlation $(r=0.99)$ between serum IL6 and endogenous IL6 production. Immediately after starting the treatment with the anti-IL6 cMab, the IL6 production decreased in all patients to below $3 \mu \mathrm{g} / \mathrm{d}$ (Fig. 4 $B)$. During the anti-IL6 treatment free IL6 levels and endogenous IL6 production remained low. The pretreatment values were not reached within the study period, except for patients 5 and 9, who developed active infections during anti-IL6 treatment. In these two patients IL6 production rapidly increased from normal to $128 \mu \mathrm{g} / \mathrm{d}$ in patient 5 and to $1,208 \mu \mathrm{g} / \mathrm{d}$ in patient 9 (Fig. 4 B).

\section{Discussion}

The pharmacological data obtained in nine patients with multiple myeloma treated with chimeric anti-IL6 Mab have several interesting aspects. First, we found a long $t_{1 / 2}$ of this cMab and could not detect human anti-chimeric antibodies. Second, high levels of IL6 were circulating in the form of (inactive) immune complexes. Third, using kinetic data for both bound and free IL6, we were able to calculate endogenous IL6 production during nonsteady state conditions. These data indicate the existence of a positive feed back loop between IL6 and IL6 production in MM.

The median $t_{1 / 2}$ of this cMab was $17.6 \mathrm{~d}$, i.e., in the same range as the plasma half-life time of normal $\mathrm{IgG}$ in humans (22). In agreement with this long $t_{1 / 2}$ we could not detect human anti-chimeric antibodies in the plasma of these nine patients until day 100. Thus, the immunogenicity of this cMab seems to be low. This is in contrast to murine (anti-IL6) Mab which often results in the induction of human anti-mouse antibodies (9-11), even in patients with B cell malignancies, known to have acquired deficiencies in cellular and humoral immunity.

Because of the long $t_{1 / 2}$, the present dosage scheme resulted in a progressive rise in serum levels of the antibody (Fig. $2 \mathrm{~A}$ ). Several studies in animals and humans have shown that the use of anti-IL6 Mab led to accumulation of circulating IL6 in the form of immune complexes $(9,23-27)$. We also found high levels of circulating IL6 bound to the cMab (Fig. 2 B). A key question

\section{free \\ IL6 $(\mathrm{pg} / \mathrm{ml})$}

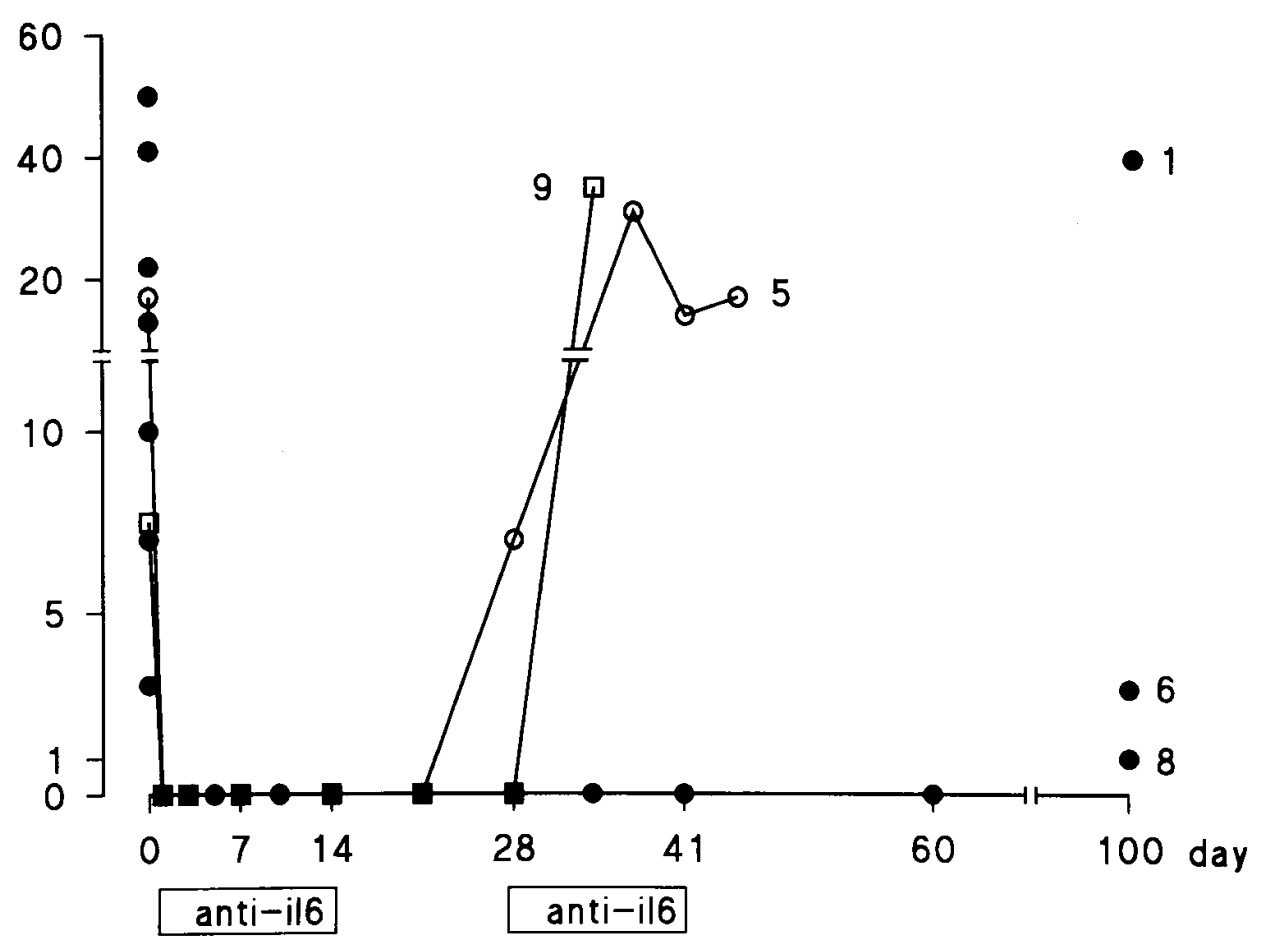

Figure 3. Free IL6 levels; patients 5 and 9 developed an active infection (see Results). Day 60: $n=7$. Day 100: $n=3$. Solid circle: patients $1-4$ and 6-8. Open circle: patient 5. Square: patient 9. 
is whether this complexed IL6 has biological activity. If so, treatment with anti-IL6 might result in disease progression cq. clinical deterioration. Three observations make this possibility unlikely. First, during anti-IL6 treatment CRP levels (completely IL6 dependent; 28 ) decreased to below detection level (3 mg/liter). Second, in the three patients in which we were able to test it, we found a blockage or decreased proliferation of the myeloma cells in the bone marrow (21). Apart from the observed disease stabilization these data indicate that these circulating complexes were not active in vivo. Third, we did not observe an accelerated disease course after the anti-IL6 treatment. Martens et al. concluded from their study in mice that more than 1,000-fold molar excess of antibody is needed for neutralization of the biological activity (24). It is important to note that their Mab had a much higher dissociation constant $\left(10^{-8}-10^{-10} \mathrm{M}\right)$ than the chimeric Mab used in our study $\left(6.25 \times 10^{-12} \mathrm{M}\right)$, whereas the association constant of IL6 with its receptor is $\sim 10^{11} \mathrm{M}^{-1}$ (29).
Lu et al. published a method to calculate the endogenous IL6 production during steady state conditions. The one patient described had a daily IL6 production of about $15 \mu \mathrm{g}$ in steady state situation (30). To perform their calculation, they had to make at least three assumptions, one of them being that IL6 was eliminated in the form of immune complexes only. This assumption was not necessary for our model. More recently, the same group described IL6 production in another 13 patients (6 MM, 7 renal carcinoma) treated with murine anti-IL6 Mab (31). They concluded that anti-IL6 treatment was only effective in low IL6 producers. The difference between their study and ours is that they used a murine anti-IL6 Mab with a higher $K_{\mathrm{d}}$ and a shorter half-life time of only three to four days $\left(t_{1 / 2}\right.$ of our cMab $>2 \mathrm{wk}$ ). Moreover, some patients developed human anti-mouse antibodies. We think that because of the long $t_{1 / 2}$ and the high affinity of our cMab, we have been able to block IL6 production at stromal level in the bone marrow more ef-

A

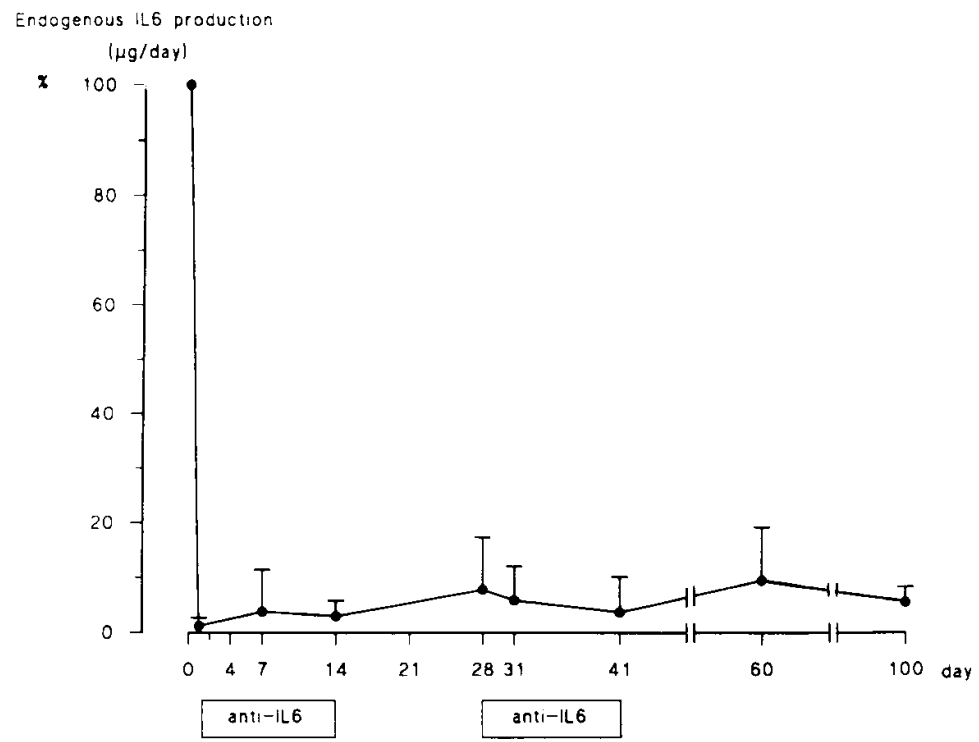

$\mathrm{B}$

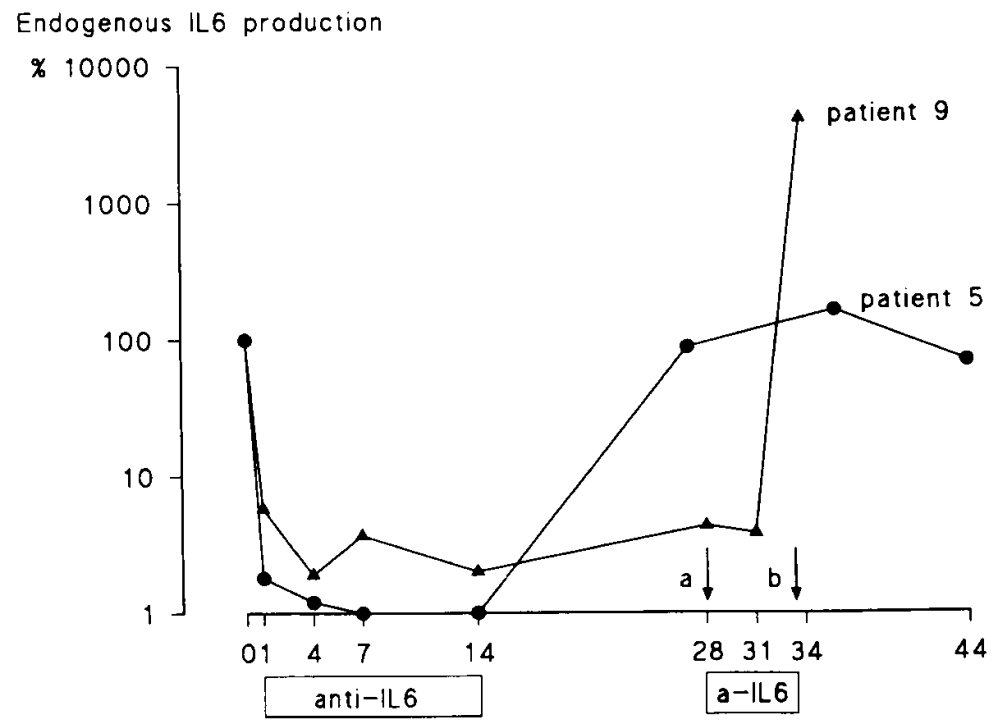

Figure 4. (A) Endogenous IL6 production $(\mu \mathrm{g} / \mathrm{d})$ in patients $1-4$ and $6-8$ as \% (and SEM) of Day 0 (pre-treatment). Day 60: $n=7$. Day 100: $n=3$. (B) Endogenous IL6 production $(\mu \mathrm{g} / \mathrm{d})$ in patient 5 and 9 as \% of Day 0 (logarithmic scale). (a) The second treatment cycle at Day 28 of anti-IL6 was not given in patient 5 because of an urinary tract infection. (b) AntiIL6 was stopped on Day 33 in patient 9 because of a septicemia. 
fectively. In our model we also took into account the elimination of free IL6. The $t_{1 / 2}$ of free IL6 is more than 1,000 times shorter than IL6 bound to the cMab, possibly due to the fact that the IL6 bound in complex cannot be cleared by the kidneys (20). In rat it was shown that ${ }^{125}$ I-rIL6 was cleared mainly by liver, skin, and kidney (32). Because of this rapid clearance of free IL6, a changing and not negligible equilibrium between free and bound IL6 will exist depending on the dissociation constant and the cMab concentration (Fig. 1). We were able to put forward a method to calculate endogenous IL6 production from day to day and not only in steady state situation, because the clearance of free IL6 is taken into account.

We think it is justified to use the pharmacokinetic data on rIL6 obtained in our previous study in another group of patients $\left(\right.$ median $t_{1 / 2}$ of IL6 $=19.5 \mathrm{~min}$; median $\mathrm{Vd}=52.3 \mathrm{li}-$ ters)(18), because the patients in our study were of similar age and had almost equal body mass index as well as normal liver and kidney functions. Moreover Castell et al. found in rats a half-life time of IL6 in approximately the same range (33). That the $t_{1 / 2}$ of the (monomeric) complex is similar to the $t_{1 / 2}$ of the free Mab has been described by others (20), but the other assumption, i.e., the $K_{\mathrm{d}}$ in vitro is equal to the $K_{\mathrm{d}}$ in vivo, cannot be verified, but seems reasonable. We are not aware of data from literature providing arguments against these assumptions.

To further controlate our finding of the inhibition of endogenous IL6 production by the anti-IL6 treatment, we used our formula to calculate the total serum IL6 concentrations assuming that the pretreatment endogenous IL6 production would remain constant during anti-IL6 treatment. Because this situation would have resulted in total IL6 levels 10-15 times the levels we have actually measured, it is highly unlikely that our data are due to an (in vitro) artefact.

One of the most intriguing findings of our study was the near complete inhibition of endogenous IL6 production by anti-IL6. In 35 healthy controls the upper limit of serum IL6 was found to be $3.2 \mathrm{pg} / \mathrm{ml}$ (34). Using our formula, it can be calculated that in healthy persons the maximum endogenous IL6 production is $6.7 \mu \mathrm{g} / \mathrm{d}$. Thus, in our MM patients the IL6 production before therapy is significantly increased (median $60 \mu \mathrm{g} / \mathrm{d}$; see Table III). In our study the free IL6 level of patients with multiple myeloma rapidly decreased immediately after starting the anti-IL6 cMab treatment due to binding to the cMab. Concomitantly the IL6 production rapidly declined to absolute values under $3 \mu \mathrm{g} / \mathrm{d}$, i.e., within the normal range (Fig. 4).

At present, the exact mechanism involved in the plasma cell induced IL6 secretion in BMSC is unknown, but we found that intimate cell-cell contact between the plasma cell and the BMSC was absolutely necessary (35). Whatever the exact sequence of events at the cellular level, our IL6 production data indicate, in patients with multiple myeloma, the existence of a positive feed back mechanism as to the production of IL6.

To our knowledge this is the first description of a positive feed back mechanism between IL6 and IL6 production in MM patients. The data of patients 5 and 9 are intriguing because they show us that despite high levels of circulating cMab, large amounts of IL6 can be produced, leading to CRP levels of 130 $\mathrm{mg} /$ liter in patient 5 and $245 \mathrm{mg} /$ liter in patient 9 (data not shown here). In patient 5 (having an urinary tract infection) the endogenous IL6 production increased to $128.4 \mu \mathrm{g} / \mathrm{d}$. In patient 9 , who developed an acute pneumonia with a septicemia, the endogenous IL6 production increased to $1,208 \mu \mathrm{g} / \mathrm{d}$. The total IL6 level that day was $356.000 \mathrm{pg} / \mathrm{ml}$. Thus, the positive feed back mechanism described above for myeloma cell induced IL6 production by BMSC, seems to lack infection-induced, endotoxin/ TNF mediated IL6 production (by monocytes/macrophages, or endothelial cells?).

In conclusion, we have provided a method to calculate whole body endogenous IL6 production from day to day. We have observed that in MM patients the endogenous IL6 production is significantly increased when compared to healthy individuals. Treatment with chimeric monoclonal anti-IL6 antibodies normalizes endogenous IL6 production, probably by blocking a positive feed back loop in myeloma associated IL6 production. Chimeric anti-IL6 Mab have a long half-life time, a low immunogenicity, and are able to block IL6 dependent processes in vivo, but do not prevent infection-induced IL6 production.

\section{References}

1. Anderson, K., R. Jones, C. Morimoto, P. Leavitt, and B. Barut. 1989. Response patterns of purified myeloma cells to hematopoietic growth factors. Blood. 73:1915-1924.

2. Kawano, M., T. Hirano, T. Matsuda, T. Taga, Y. Horii, K. Iwato, H. Asaoku, B. Tang, H. Tanaka, A. Kuramoto, and T. Kishimoto. 1988. Autocrine generation and requirement of BSF 2/IL6 for human multiple myelomas. $\mathrm{Na}$ ture (Lond.). 332:83-85.

3. Klein, B., X.G. Zhang, M. Jourdan, J. Content, J. Houssiau, L. Aarden, M. Piechaczyk, and R. Bataille. 1989. Paracrine rather than autocrine regulation of myeloma cell growth and differentiation by IL6. Blood. 73:517-526.

4. Nordan, R., J. Pumphrey, and S. Rudikoff. 1987. Purification and NH2terminal sequence of a plasmacytoma growth-factor derived from the murine macrophage cell line P 388 D1. J. Immunol. 139:813-817.

5. Zhang, X.G., B. Klein, and R. Bataille. 1989. IL6 is a potent myeloma cell growth factor in patients with aggressive MM. Blood. 74:11-13.

6. van Oers, M., H., van Zaanen, and H. Lokhorst. 1993. Interleukin-6, a new target for therapy in multiple myeloma? (review). Ann. Hematol. 66:219223.

7. Bataille, R., M. Jourdan, X.G. Zhang, and B. Klein. 1989. Serum levels of IL6, a potent myeloma cell growth factor, as a reflect of disease severity in plasma cell dyscrasias. J. Clin. Invest. 84:2008-2011.

8. Klein, B., X.G. Zhang, M. Jourdan, J. Boiron, M. Portier, Z. Lu, J. Wijdenes, J. Brochier, and R. Bataille. 1990. IL6 is the central tumor growth factor in vitro and in vivo in multiple myeloma (review). Eur. Cytokine Net. 1: 193-201.

9. Klein, B., J. Wijdenes, X.G. Zhang, M. Jourdan, J. Boiron, J. Brochier, J. Liautard, M. Merlin, C. Clement, B. Morel-Fournier, Z. Lu, P. Mannoni, J. Sany, and R. Bataille. 1991. Murine anti-interleukin-6 monoclonal antibody therapy for a patient with plasma cell leukemia. Blood. 78:1198-1204.

10. Bataille, R., B. Barlogie, Z. Lu, J. Rossi, T. Lavabre-Bertrand, T. Beck, J. Wijdenes, J. Brochier, and B. Klein. 1995. Biologic effects of anti-interleukin 6 murine monoclonal antibody in advanced multiple myeloma. Blood. 86:685691.

11. Hoffman, T. 1990. Anticipating, recognizing and preventing hazards associated with in vivo use of monoclonal antibodies: Special considerations related to human anti-mouse antibodies. Cancer Research. (suppl); 50:1049s$1050 \mathrm{~s}$.

12. Durie, B., and S. Salmon. 1975. A clinical staging system for multiple myeloma. Cancer. 36:842-854.

13. Brakenhoff, J., M. Hart, E. De Groot, F. Di Padova, and L. Aarden. 1990. Structure-function analysis of human IL6. Epitope mapping of neutralizing monoclonal antibodies with amino- and carboxyl- terminal deletion mutants. J. Immunol. 145:561-568.

14. Ehlers, M., J. Grotzinger, F. de Hon, J. Mullberg, J. Brakenhoff, J. Liu, A. Wollmer, and S. Rose-John. 1994. Identification of two novel regions of human IL-6 responsible for receptor binding and signal transduction. J. Immunol. 153:1744-1751.

15. Aarden, L., E. De Groot, O. Schaap, and P. Lansdorp. 1987. Production of hybridoma growth factor by human monocytes. Eur. J. Immunol. 17:14111416.

16. Aarden, L. 1991. Plasmacytomas. In Mechanisms of B Cell Neoplasm. F. Melchens and M. Potter, editors. ER, Basel, Switzerland. 429-433.

17. Metzler, C., and D. Weiner. 1989. PC Nonlin. SCI Software, Lexington, KY.

18. Stouthard, J., J. Romijn, T. van der Poll, E. Endert, S. Klein, P. Bakker, C. Veenhof, and H. Sauerwein. 1995. Endocrinologic and metabolic effects of 
interleukin-6 in humans. Am. J. Phys. 268:813-819.

19. Hell, M., L. Boeije, E. de Groot, A. de Vos, and L. Aarden. 1991.

ELISA for IL6. J. Immunol. Methods. 138:47-56.

20. Klein, B., and H. Brailly. 1995. Cytokine-binding proteins: stimulating antagonists. Immunol. Today. 16:216-220.

21. van Zaanen, H., H. Lokhorst, L. Aarden, I. Rensink, S. Warnaar, and M. van Oers. 1994. Phase I/II multiple-dose pilot study of chimeric monoclonal anti-IL6 antibody in MM. Br. J. Haematol. 87:Suppl.I. 238 (Abstr.).

22. Wintrobe's Clinical Hematology. Ninth ed., 1993. Vol. 1. 450. Lea \& Febiger, Philadelphia/London.

23. May, L., R. Neta, L. Moldawer, J. Kenney, K. Patel, and P. Sehgal. 1993. Antibodies chaperone circulating IL-6. Paradoxical effects of anti-IL6 "neutralizing" antibodies in vivo. J. Immunol. 151:3225-3236.

24. Martens, E., C. Dillen, W. Put, H. Heremans, J. Van Damme, and A. Billiau. 1993. Increased circulating interleukin 6 activity in endotoxin- challenged mice pretreated with anti-IL6 antibody is due to IL6 accumulated in antigen-antibody complexes. Eur. J. Immunol. 23:2026-2029.

25. May, L., K. Patel, D. Garcia, M. Ndubuisi, S. Ferrone, A. Mittelman, A. Mackiewicz, and P. Sehgal. 1994. Sustained high levels of circulating chaperoned Interleukin-6 after active specific cancer immunotherapy. Blood. 84:1887-1895.

26. Mihara, M., Y. Koishihara, H. Fukui, K. Yasukawa, and Y. Ohsugi. 1991. Murine anti-human IL6 monoclonal antibody prolongs the half-life time in circulating blood and thus prolongs the bioactivity of human IL6 in mice. Immunology. 74:55-59.

27. Heremans, H., C. Dillen, W. Put, J. Van Damme, and A. Billiau. 1992. Protective effect of anti-IL6 antibody against endotoxin, associated with para- doxically increased IL6 levels. Eur. J. Immunol. 22:2395-2401.

28. Heinrich, P., J. Castell, and T. Andus. 1990. Interleukin-6 and the acute phase response (review). Biochem. J. 265:621-636.

29. Yamazaki, K., T. Taga, Y. Hirata, H. Yawata, Y. Kawanishi, B. Seed, T. Taniguchi, T. Hirano, and T. Kishimoto. Cloning and expression of the human interleukin-6 (BSF-2/IFNß2) receptor. Science (Wash. DC). 241:825-828.

30. Lu, Z., J. Brochier, J. Wijdenes, H. Brailly, R. Bataille, and B. Klein. 1992. High amounts of circulating IL6 in the form of monomeric immune complexes during anti-IL6 therapy. Towards a new methodology for measuring overall cytokine production in human in vivo. Eur. J. Immunol. 22:2819-2824.

31. Lu, Z., H. Brailly, J. Wijdenes, R. Bataille, J. Rossi, and B. Klein. 1995. Measurement of whole body IL-6 production: prediction of the efficacy of antiIL-6 treatments. Blood. 86:3123-3131.

32. Castell, J., J. Klapproth, V. Gross, E. Walter, T. Andus, L. Snyers, J. Content, and P. Heinrich. 1990. Fate of interleukin-6 in the rat. Eur. J. Biochem. 189:113-118.

33. Castell, J., T. Geiger, V. Gross, T. Andus, E. Walter, T. Hirano, T. Kishimoto, and P. Heinrich. 1988. Plasma clearance, organ distribution and target cells of interleukin 6/ hepatocyte-stimulating factor in rat. Eur. J. Biochem. 177: 357-361.

34. Tienhaara, A., K. Pulkki, K. Matilla, K. Irjala, and T. Pelliniemi. 1994 Serum immunoreactive IL6 and CRP levels in patients with MM at diagnosis. Br. J. Haematol. 86:391-393.

35. Lokhorst, H., T. Lamme, M. de Smet, S. Klein, R. de Weger, R. van Oers, and A. Bloem. 1994. Primary tumor cells of myeloma patients induce IL6 secretion in long-term bone marrow cultures. Blood. 84:2269-2277. 